\title{
Tecnologias Utilizadas para a Reutilização, Reciclagem e Valorização Energética de Pneus no Brasil
}

\author{
Carlos Alberto F. Lagarinhos, Jorge Alberto S. Tenório \\ Departamento de Engenharia Metalúrgica e de Materiais, EPUSP
}

\begin{abstract}
Resumo: Os pneus usados estão se tornando um problema mundial. O descarte de pneus cresce ano após ano em todo o mundo. Pouca importância foi dada ao descarte de pneus em muitos países. No Brasil, em 1999, foi aprovada a Resolução $\mathrm{n}^{\circ}$ 258/99 do CONAMA (Conselho Nacional do Meio Ambiente) que instituiu a responsabilidade do produtor e do importador pelo ciclo total do produto, ou seja, a coleta, o transporte e a disposição final. Desde 2002, os fabricantes e importadores de pneus devem coletar e dar a destinação final para os pneus usados. Segundo essa lei, os distribuidores, revendedores, reformadores e consumidores finais são co-responsáveis pela coleta dos pneus servíveis e inservíveis, os quais devem colaborar com a coleta. Neste trabalho serão apresentadas as tecnologias utilizadas no Brasil para a reutilização, reciclagem e valorização energética, além de um fluxograma do processo de logística reversa dos pneus novos e usados, dados estatísticos dos canais de distribuição, objetivo da reciclagem e a disposição final, no período de 2002 a 2006. Em 2006, foram reciclados 240,62 mil toneladas de pneus inservíveis, o equivalente a 48,12 milhões de pneus de automóvel. As atividades de laminação, trituração e fabricação de artefatos de borracha representaram 50,02\% do total destinado, o co-processamento em fornos de clínquer representou $35,73 \%$, a regeneração de borracha sintética representou $13,22 \%$ e a extração e tratamento de minerais $1,03 \%$.
\end{abstract}

Palavras-chave: Reciclagem, pneus, tecnologias.

\section{Technologies for Reusing, Recycling and Energetic Valorization of Tires in Brazil}

Abstract: Used tires have become a worldwide problem. The discarding of tires rises year after year all over the world. So far little importance has been given to the discarding of tires in many countries. In 1999, the CONAMA (National Council for the Environment) resolution 258/99 made the producer or importer as responsible for the total cycle of the product in Brazil, including the means of collection, transportation and final destination to the product. Since 2002, the manufacturers and importers of tires must collect and give the final destination to the used tires. The distributors, retailers, re-modelers and final consumers are co-responsible for the collection of the used or unserviceable tires. In this study we review the technologies for reusing, recycling and energetic valorization of tires, in addition to presenting a flowchart of the reverse logistic process for new and used tires. Also included are statistical data of distribution channels, recycling goals and final destination for the used tires in the period from 2002 to 2006. In 2006, 240.62 thousand tons of unserviceable tires were recycled, which correspond to 48.12 million of automobile tires. The activities of laminating, grinding and manufacturing of rubber artifacts represented $50.02 \%$ of the total; the co-processing in clinker ovens represented $35.73 \%$; the synthetic rubber regeneration represented $13.22 \%$ while $1.03 \%$ was used in the extraction and treatment of minerals.

Keywords: Recycle, tires, technologies.

\section{Introdução}

O processo de reciclagem de borracha é tão antigo quanto o próprio uso da borracha na indústria. Já em 1909, em Heipizig na Alemanha, havia a trituração e a separação da borracha de vários artefatos. A razão para o crescimento da indústria da reciclagem em 1909 foi a falta de abastecimento da borracha e o alto custo de aquisição da borracha natural ${ }^{[1]}$. Em 1960 a borracha reciclada era fornecida para as indústrias de artefatos de borracha. Óleos importados baratos, difusão do uso da borracha sintética e desenvolvimento de pneus radiais diminuíram o interesse em se triturar os pneus inservíveis. A tecnologia desenvolvida nesta época não era ideal para triturar os pneus radiais.
Os pneus diagonais ou convencionais são utilizados em ônibus e caminhão. Os pneus radiais são utilizados em automóveis, ônibus, caminhões, veículos fora-de-estrada. Uma das grandes dificuldades encontradas pelas empresas que trituram os pneus é o corte da malha de aço de pneus radiais, além dos talões. Os pneus convencionais são mais fáceis de serem triturados.

\section{Produção e Importação de Pneus}

A produção mundial de pneus novos em 2005 foi de 1,32 bilhões em todo o mundo. Já o descarte de pneus usados chega a atingir, anualmente, a marca de quase 1 bilhão de unidades ${ }^{[2]}$.

Autor para correspondência: Carlos Alberto F. Lagarinhos, Departamento de Engenharia Metalúrgica e de Materiais, Escola Politécnica, Universidade de São Paulo, Av. Prof. Mello Moraes 2462, CEP: 05508-900, São Paulo, SP, Brasil. E-mail: clagarinhos@usp.br 


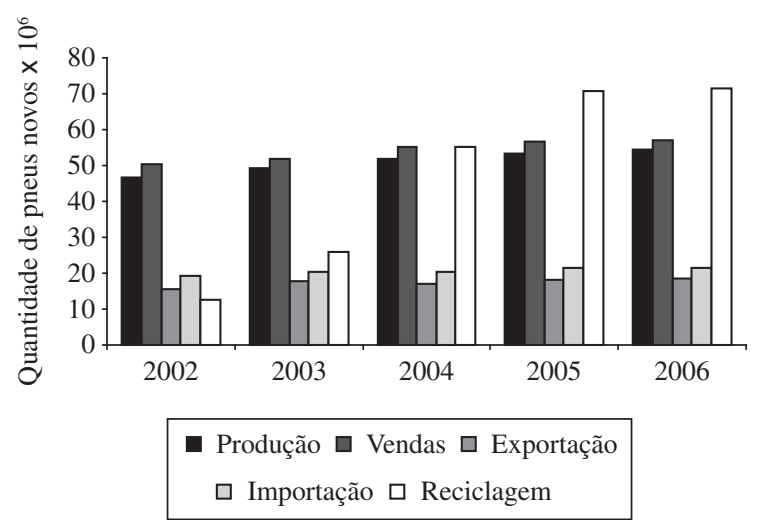

Figura 1. Canais de distribuição e objetivo da reciclagem de pneus no período de 2002 a 2006.

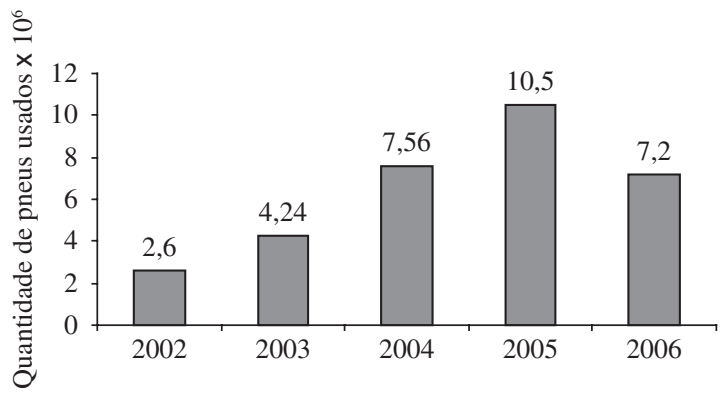

Figura 2. Importação de pneus usados no período de 2002 a 2006.

No Brasil, foram produzidos em 2006 54,5 milhões de pneus, importados 21,4 milhões de pneus e exportados 18,7 milhões de pneus ${ }^{[3]}$. Podemos observar na Figura 1, a produção, importação, exportação e o objetivo da reciclagem de pneus no período de 2002 a 2006.

Além disso, em 2006 foram importados 7,2 milhões de pneus usados para o processo de reforma e venda como pneus meia-vida ${ }^{[4]}$. Os pneus usados entram no Brasil por meio de liminares que autorizam a importação para o processo de reforma. A Figura 2 mostra a quantidade de pneus importados no período de 2002 a 2004.

\section{Legislação Ambiental}

Em 1999 foi aprovada a Resolução $n^{\circ} 258 / 99$ do CONAMA (Conselho Nacional do Meio Ambiente) que instituiu a responsabilidade do produtor e do importador pelo ciclo total do produto, ou seja, a coleta, o transporte e a disposição final. Desde 2002 os fabricantes e importadores de pneus devem coletar e dar a destinação final para os pneus usados. Os distribuidores, revendedores, reformadores e consumidores finais são co-responsáveis pela coleta dos pneus servíveis e inservíveis, os quais devem colaborar com a coleta ${ }^{[5]}$.

A partir de 2002 para cada 4 pneus produzidos ou importados (novos ou reformados) um pneu inservível deveria ser reciclado. A partir de 2003 a relação deveria ser de dois pneus produzidos ou importados (novos ou reformados) para um pneu inservível reciclado. Em 2004 a proporção foi de um pneu produzido ou importado novo para um pneu inservível reciclado. Em 2005 a relação cresceu para cada 4 pneus produzidos ou importados novos, cinco pneus usados deveriam ser reciclados; e, para cada 3 pneus importados reformados de qualquer tipo deveriam ser reciclados 4 pneumáticos usados.

No quinto ano de vigência dessa legislação, as normas e os procedimentos estabelecidos nesta Resolução seriam revisados. Desde 2005 a Resolução no 258/99 encontra-se em processo de revisão pelo IBAMA (Instituto Brasileiro do Meio Ambiente e dos Recursos Naturais Renováveis), em 2006 a meta é de para quatro pneus produzidos ou importados novos, cinco pneus usados deveriam ser reciclados.

\section{Definição de Pneus ou Pneumáticos}

A primeira iniciativa de definição de pneus veio com a Resolução CONAMA n ${ }^{\circ}$ 258/99 ${ }^{[5]}$ :

- Pneu ou pneumático: todos os artefatos infláveis, constituídos basicamente por borracha e materiais de reforço, utilizados para rodagem de veículos;

- Pneu ou pneumático novo: aquele que nunca foi utilizado para rodagem, sob qualquer forma, enquadrandose, para efeito de importação;

- Pneu ou pneumático reformado: todo pneumático que foi submetido a algum tipo de processo industrial com o fim especifico de aumentar sua vida útil de rodagem em meios de transporte, tais como recapagem, recauchutagem ou remoldagem, enquadrando-se, para efeitos de importação; e

- Pneu ou pneumático inservível: aquele que não mais se presta para o processo de reforma que permita condição de rodagem adicional.

A partir da Resolução CONAMA no 258/99 veio a necessidade de ampliar o conceito ou definições para normalização dos conceitos, advindo: Portaria $\mathrm{n}^{\circ} 5$ - INMETRO, 14 de janeiro de $2000^{[6]}$; Nota Técnica - INMETRO DQUAL/ DIPAC/ $\mathrm{n}^{\circ}$ 083/2000, 03 de outubro de $2000^{[7]}$ e a Portaria $\mathrm{n}^{\circ} 133$ - INMETRO, 27 de setembro de $2001^{[8]}$.

- Pneu novo: pneu que não sofreu qualquer uso, nem foi submetido a qualquer tipo de reforma e que não apresenta sinais de envelhecimento nem deteriorações de qualquer origem;

- Pneu usado: pneu que foi submetido a qualquer tipo de uso e/ou desgaste.

- Pneu reformado: pneu reconstruído a partir de um pneu usado, onde se repõem uma nova banda de rodagem, podendo incluir a renovação da superfície externa lateral (flancos), abrangendo os seguintes métodos e processos: recapagem, recauchutagem e remoldagem;

- Pneu radial: pneu cuja carcaça é constituída de uma ou mais lonas cujos fios, dispostos de talão a talão, são colocados substancialmente a $90^{\circ}$, em relação à linha de centro da banda de rodagem, sendo essa carcaça es- 
tabilizada por uma cinta circunferencial constituída de duas ou mais lonas substancialmente inextensíveis;

- Pneu diagonal: pneumático cuja carcaça é constituída de lonas, cujos fios dispostos de talão a talão são colocados em ângulos cruzados, uma lona em relação a outra, substancialmente menores que $90^{\circ}$ em relação à linha de centro da banda de rodagem.

\section{Composição dos Pneus de Automóvel e Carga}

A composição e a porcentagem em peso de cada material utilizado para a construção dos pneus de automóvel, caminhão e ônibus são apresentadas na Tabela 1. Além disso, é apresentado o peso médio do pneu novo e inservível, conforme a Instrução Normativa no 8 do IBAMA ${ }^{[9,10]}$ :

\section{Poder Calorífico dos Pneus}

O pneu é uma excelente fonte alternativa de combustível. Isto pode ser verificado comparando-se os valores do poder calorífico do pneu com outros materiais indicados na Tabela 2.

\section{Processo de Queima dos Pneus}

Estudos de pequena escala sobre a combustão de pneus ao ar livre entre 100 a $2000{ }^{\circ} \mathrm{C}$ revelaram que as existências de espaços vazios no meio dos pneus proporcionam um meio de transporte de oxigênio, aparenta ser o mecanismo de controle para sustentar o processo de combustão ${ }^{[12]}$.

A degradação térmica a uma temperatura inferior a $250{ }^{\circ} \mathrm{C}$ produz um alcatrão oleoso. Os hidrocarbonetos gasosos com 1 a 5 átomos de carbono (metano, etano, isopropeno,

Tabela 1. Composição dos materiais utilizados nos pneus de passeio e carga por peso (Adaptado) $)^{[9,10]}$.

\begin{tabular}{|c|c|c|}
\hline Materiais & $\begin{array}{c}\text { Pneu de } \\
\text { automóvel }(\%)\end{array}$ & $\begin{array}{c}\text { Pneu de carga } \\
(\%)\end{array}$ \\
\hline Borracha natural & 14 & 27 \\
\hline Borracha sintética & 27 & 14 \\
\hline $\begin{array}{l}\text { Negro de fumo } \\
\text { (Carbono) }\end{array}$ & 28 & 28 \\
\hline Aço & $14-15$ & $14-15$ \\
\hline $\begin{array}{l}\text { Tecido, aceleradores, } \\
\text { antiozônio, óleos etc. }\end{array}$ & $16-17$ & $16-17$ \\
\hline Peso total & $\begin{array}{l}\text { Peso médio do } \\
\text { pneu novo } 8,5 \\
\text { kg. No Brasil, o } \\
\text { pneu inservível } \\
\text { pesa } 5 \mathrm{~kg} \text {, con- } \\
\text { forme a instru- } \\
\text { ção normativa } \\
\text { n }^{\circ} 8 \text { do IBAMA, } \\
\text { de } 15 \text { de maio de } \\
2002 \text {. }\end{array}$ & $\begin{array}{l}\text { No Brasil, o } \\
\text { pneu inservível } \\
\text { pesa } 40 \mathrm{~kg} \text {, con- } \\
\text { forme a instru- } \\
\text { ção normativa } \\
\text { n }^{\circ} 8 \text { do IBAMA, } \\
\text { de } 15 \text { de maio de } \\
2002 \text {. }\end{array}$ \\
\hline
\end{tabular}

Tabela 2. Poder calorífico de alguns materiais (Adaptado) ${ }^{[11]}$.

\begin{tabular}{lc}
\hline \multicolumn{1}{c}{ Material } & $\begin{array}{c}\text { Poder calorífico } \\
\text { (kcal/kg) }\end{array}$ \\
\hline Polietileno (PE) & 10382 \\
Óleo combustível & 10000 \\
Poliestireno (PS) & 9122 \\
Plásticos diversos & 7833 \\
Carvão betuminoso & 7778 \\
Pneus & 7667 \\
Carvão antracito & 7500 \\
Folhas (10\% umidade) & 4436 \\
Jornal & 4417 \\
Papel Corrugado & 3913 \\
Papel & 3778 \\
Revistas & 2917 \\
Resíduo de Serviço de Saúde - RSS & 2667 \\
Turfa & 2000 \\
Folhas (50\% de umidade) & 1964 \\
Resíduos de alimentos & 1317 \\
Madeira verde & 1167 \\
Gás natural & 620 \\
\hline
\end{tabular}

butadieno e propano), são produzidos a temperaturas entre 250 a $450{ }^{\circ} \mathrm{C}$.

Vários estudos já comprovaram que a queima a céu aberto, independente da quantidade, gera emissões com um efeito mutagénico. Os pneus inteiros, como provocam taxas de combustão superiores quando comparados aos pneus triturados, geram emissões orgânicas mais elevadas ${ }^{[12]}$.

A Environmental Protection Agency - EPA fez uma simulação de queima de pneus usados em uma câmara de combustão controlada, realizando um estudo sobre as emissões produzidas. Estas emissões caracterizam uma queima real, porém suas concentrações podem não ser representativas ${ }^{[13]}$. Os dados apresentados revelaram que as emissões de compostos orgânicos semivoláteis representavam entre 10 a $50 \mathrm{~g} / \mathrm{kg}$ do pneu queimado, sendo maiores as emissões de hidrocarbonetos mono e poliaromáticos ${ }^{[13]}$. Verificaram-se, ainda, emissões de outros compostos, como o benzeno, em concentrações maiores que $1 \mathrm{ppm}$, podendo constituir risco a saúde pública. Registrou-se também a presença de zinco e chumbo nas emissões gasosas ${ }^{[13]}$.

\section{Potencial de Contaminação do Ambiente}

Os dois subprodutos que constituem o maior risco de contaminação ao meio ambiente são: o óleo pirolítico e as cinzas. Devido às condições de diminuição da quantidade de oxigênio no ar e o calor intenso que se gera durante uma queima incontrolada de pneus, ocorrem reações de pirólise, produzindo como consequiência um alcatrão oleoso. Esse produto do óleo pirolítico consiste em uma mistura de nafta, benzeno, tiazóis, aminas, etilbenzeno, tolueno e outros hi- 
drocarbonetos. Existem igualmente metais como o cádmio, o cromo, o níquel e o zinco ${ }^{[12]}$.

A produção de óleo pirolítico ocorre a uma temperatura de $200{ }^{\circ} \mathrm{C}$. A água utilizada para combater os incêndios em grandes pilhas de pneus aumenta a produção de óleo pirolítico e proporciona um meio eficaz para o seu transporte e contaminação dos solos e das águas superficiais e subterrâneas.

Análises das cinzas, produzidas de um subproduto da combustão ao ar livre de pneus, revelam a presença comum de metais pesados, que podem existir em altas concentrações, como no caso do chumbo, do cádmio e do zinco. As cinzas volantes apresentam elevado teor em zinco. Foram feitas análises laboratoriais de amostras de solos retiradas do local onde ocorreu uma grande queima de pneus na cidade de Bakersfield nos Estados Unidos, revelando que a massa total de zinco presente excedia o limite de concentração de metais no solo permitido nos EUA $5000 \mathrm{mg} / \mathrm{kg}$, sendo que os valores medidos no local estavam entre 7800 e $15800 \mathrm{mg} / \mathrm{kg}$. Na cidade de Panoche EUA, os valores medidos estavam entre 32800 a $156000 \mathrm{mg} / \mathrm{kg}$, no entanto, os valores existentes no solo abaixo das cinzas encontravam-se dentro dos limites previstos. Em Rhinehart, verificaram-se igualmente valores elevados de zinco em águas superficiais existentes perto do local da queima e no solo do local. A comparação entre a concentração de zinco que existia antes da queima que era 93 ppm, e após a queima dos pneus 2880 ppm, mostram um aumento significativo ${ }^{[13]}$.

Todos estes impactos ambientais negativos gerados pela queima dos pneus ao ar livre, torna necessária à tomada de uma série de medidas relativas ao armazenamento de pneus em aterros, em unidades de pré-tratamento, co-processamento, bem como o acondicionamento de pneus após a sua fabricação.

\section{Logística Reversa dos Pneus}

A logística reversa é uma nova área da logística empresarial que planeja, opera e controla o fluxo, e as informações logísticas correspondentes, do retorno dos bens de pós-venda e de pós-consumo ao ciclo de negócios ou ao ciclo produtivo, através dos canais de distribuição reversos, agregando-lhes valores de diversas naturezas: econômico, ecológico, legal, competitivo e de imagem corporativa, entre outros ${ }^{[14]}$

A grande dificuldade da logística reversa dos pneus usados é ter as informações precisas do que vai encontrar e onde encontrar os pneus usados. No Brasil, aproximadamente 4000 revendas participam do processo de coleta de pneus usados. Além disso, existem 270 ecopontos que são pontos disponibilizados pelas prefeituras municipais através da celebração de convênios de cooperação mútua, para onde são levados e armazenados temporariamente os pneus usados recolhidos pelo serviço público ou descartados voluntariamente pela população, borracheiros, entre outros ${ }^{[17]}$.

O consumidor, ao trocar os seus pneus nos distribuidores ou lojas de revenda, pode deixar ou não os seus pneus usados, em 2004 mais de 8,2 milhões de pneus tiveram destinação desconhecida ${ }^{[3]}$. O que ocorre é que o consumidor de alguma forma acha que o pneu usado possui algum valor agregado.

Após a aprovação da Resolução no 258/99, ocorreu um aumento da cadeia de logística reversa, que é composta pelos coletores, empresas de seleção e triagem de pneus usados, pré-tratamento, reforma, co-processamento, laminadores, entre outros. A Figura 3 mostra o fluxograma do processo da logística direta e reversa dos pneus novos e usados no Brasil. Quando os consumidores deixam os pneus nos distribuidores e revendedores após a troca ou nos ecopontos ou ecobases após o término da vida útil, é realizado uma triagem, na qual os pneus podem ser classificados em servíveis ou inservíveis. Os pneus servíveis são aqueles que podem ser vendidos no comércio de pneus usados, como pneus meia-vida ou podem ser reformados, através dos processos de recapagem, recauchutagem ou remoldagem. Os pneus inservíveis são aqueles que não podem ser utilizados no processo de reforma, devido o estado da carcaça e da banda de rodagem. Os pneus inservíveis são enviados para o processo de pré-tratamento. Este processo consiste em várias operações, como: a separação da borracha, a separação do aço e as fibras têxteis. O produto final dependendo do destino é o pó-de-borracha ou lascas de pneus. Os processos mais utilizados para a trituração de pneus inservíveis são: o processo de trituração à temperatura ambiente e o processo criogênico ${ }^{[15,16]}$.

\section{Reciclagem e Destino Final de Pneus no Brasil}

$\mathrm{Na}$ pesquisa realizada foi constatado que em 2006 foram reciclados no Brasil 240,62 mil toneladas de pneus inservíveis o equivalente a 48,12 milhões de pneus de automóvel. Não está incluso neste levantamento as atividades de recauchutagem e remoldagem. No período de 2002 a 2006 foram reciclados 805,26 mil toneladas de pneus inservíveis, o equivalente a 161,05 milhões de pneus de automóvel.

Além disso, foram extintos os seguintes depósitos irregulares no Brasil no período de 2002 a 2006: Sinop-MT, 80 milhões de pneus; Jataí-GO, 80 mil pneus; Formiga-MG, 97 mil pneus; Natal-RN, 101 mil pneus; no Rio Tietê em São Paulo Capital, 240 mil pneus; Almirante Tamandaré-PR, 520 mil pneus; São José do Rio Preto-SP, 700 mil pneus e Sorocaba-SP, 10 milhões de pneus ${ }^{[17]}$.

A Figura 4 mostra a reciclagem de pneus no período de 2002 a 2006 e o objetivo da reciclagem no mesmo período. Podemos observar que o objetivo foi atingido apenas em 2002.

A Figura 5 mostra o destino final de pneus em toneladas no Brasil no período de 2002 a 2006. Podemos observar que o processo de reforma de pneus não é considerado como uma atividade de reciclagem e sim como uma atividade que prolonga a vida útil de pneus.

Em 2006, foram reformados 8,56 milhões de pneus de caminhão e ônibus, 8 milhões de pneus de automóvel, 1 milhão de pneus de motocicletas e 240 mil pneus fora-de-estrada e agrícolas $^{[18]}$. 


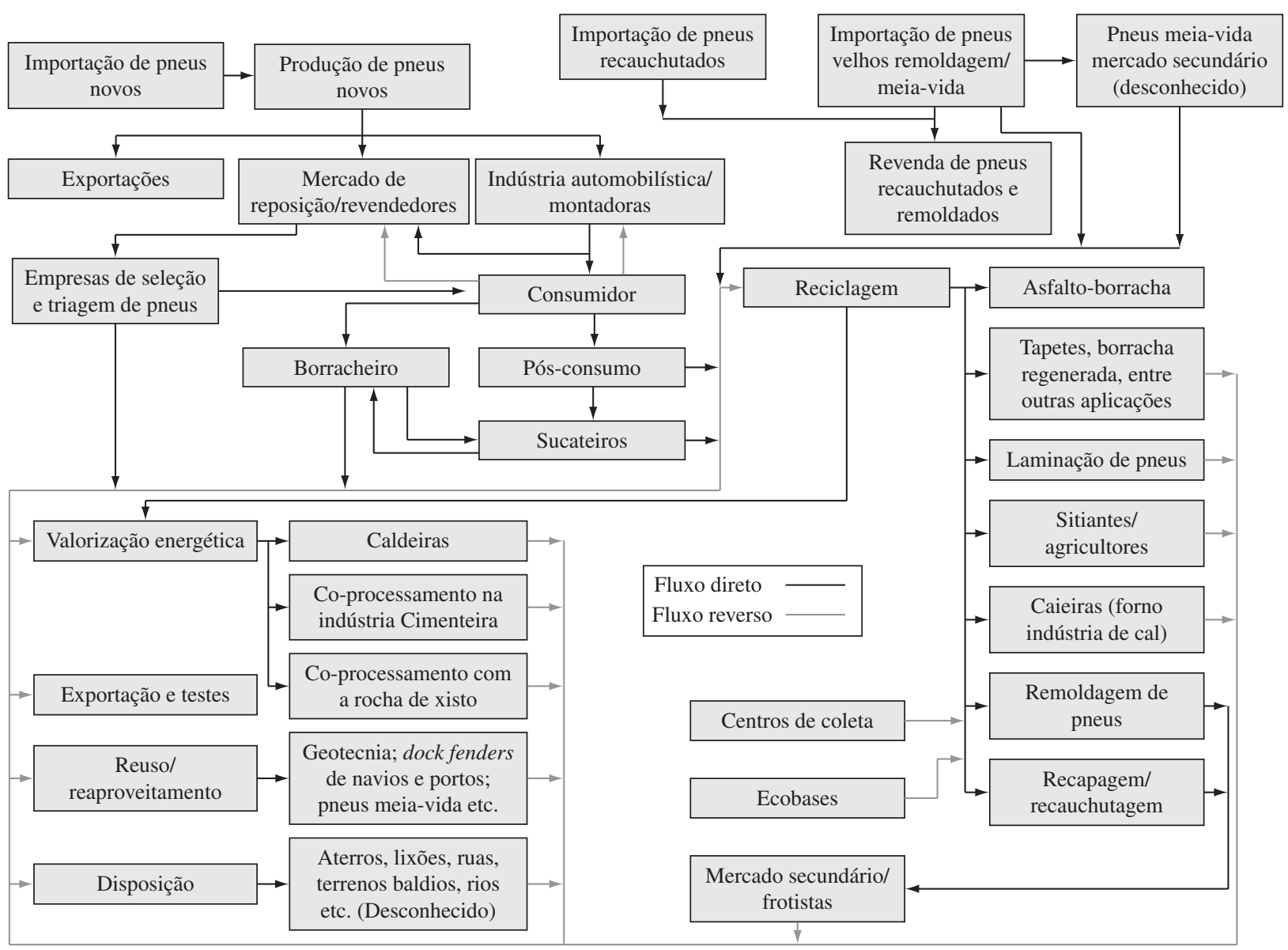

Figura 3. Fluxograma do processo de logística reversa dos pneus usados no Brasil.

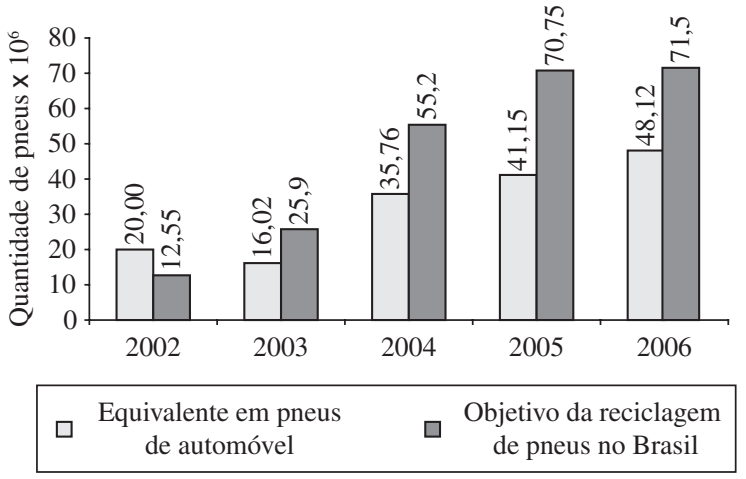

Figura 4. Reciclagem de pneus no Brasil no período de 2002 a 2006 e os objetivos da reciclagem.

A Figura 6 mostra o destino final de pneus no Brasil no período de 2002 a 2006. Podemos observar que as atividades de laminação, trituração e fabricação de artefatos de borracha em 2006 representaram 50,02\% do total destinado, o coprocessamento em fornos de clínquer representou 35,73\%, a regeneração de borracha sintética representou $13,22 \%$ e a extração e tratamento de minerais $1,03 \%$. O total destinado foi de 240,62 mil toneladas de pneus em 2006, o equivalente a 48,12 milhões de pneus de automóvel.

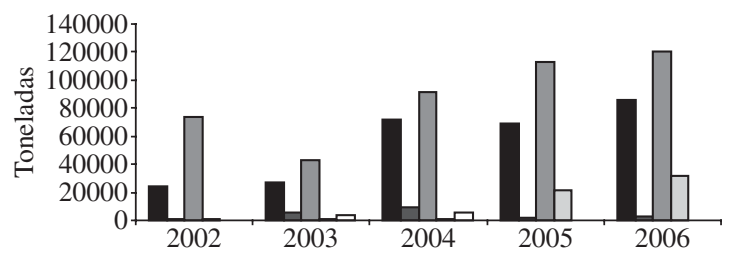

- Cimenteiras

$\square$ Extração e tratamento de minerais

$\square$ Laminação, trituração e fabricação de artefatos de borracha

$\square$ Regeneradora de borracha sintética natural

$\square$ Outros

Figura 5. Destino final de pneus no Brasil no período de 2002 a 2006, em toneladas.

\section{Tecnologias Utilizadas para a Reutilização, Reciclagem e a Valorização Energética}

As tecnologias mais utilizadas para a reutilização, reciclagem e a valorização energética de pneus usados são ${ }^{[15]}$ : recapagem, recauchutagem e remoldagem de pneus; coprocessamento em fornos de cimenteiras; retortagem ou coprocessamento de pneus com a rocha de xisto pirobetuminoso; pavimentação com asfalto-borracha; queima de pneus em caldeiras; utilização na construção civil; regeneração de 


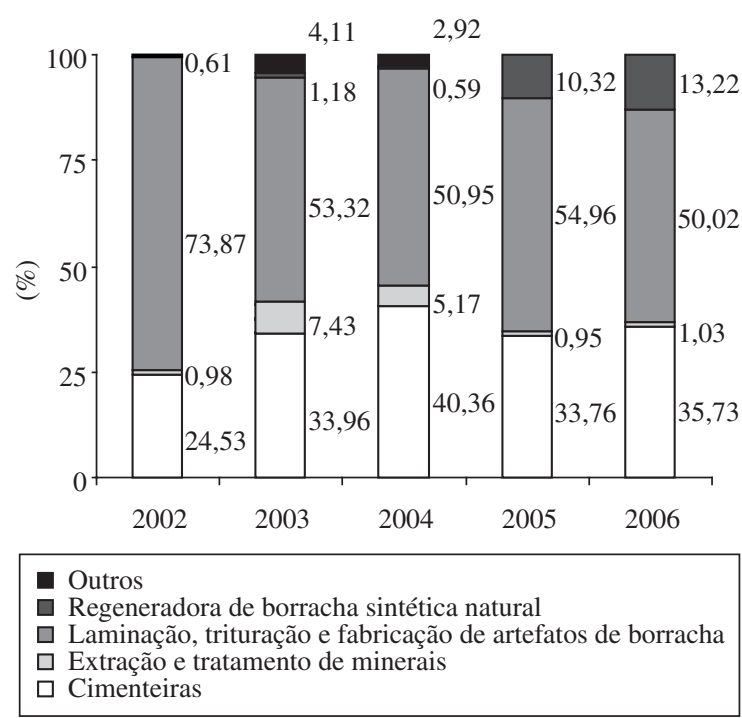

Figura 6. Destino final de pneus no Brasil no período de 2002 a 2006.

borracha; desvulcanização; obras de contenção de encostas (geotecnia); indústria moveleira; equipamentos agrícolas; mineração; tapetes para reposição da indústria; solados de sapato; cintas de sofás; borrachas de rodos; pisos esportivos; equipamentos de playground; tapetes automotivos; borracha de vedação; confecção de tatames; criadouros de peixes e camarões; amortecedores para cancelas em fazendas; leitos de drenagem em aterros, entre outras.

\section{Trituração de Pneus}

Os processos mais utilizados para a trituração de pneus são à temperatura ambiente ou com resfriamento criogênico. No Brasil o processo mais utilizado é a trituração à temperatura ambiente.

$\mathrm{O}$ processo trituração à temperatura ambiente é aquele que pode operar a temperatura máxima de $120^{\circ} \mathrm{C}$, reduzindo os pneus inservíveis a partículas de tamanhos finais de até $0,2 \mathrm{~mm}$. Este processo tem alto custo de manutenção e alto consumo de eletricidade. Nesse processo os pneus passam pelo triturador e pelo granulador. No triturador ocorre uma redução dos pneus inteiros em pedaços de 50,8 a 203,2 mm. Após a etapa de trituração os pedaços de pneus são alimentados através de um sistema transportador de correias no granulador, para a redução de pedaços de $10 \mathrm{~mm}$, dependendo do tipo de rosca montada no granulador. $\mathrm{O}$ aço é removido em um separador magnético de correias cruzadas e as frações de nylon, rayon e poliéster, são removidas pelos coletores de pó. O pó-de-borracha é separado através de um sistema de roscas e peneiras vibratórias em várias granulometrias, muitas aplicações são solicitadas para materiais finos, na faixa de 0,6 a $2 \mathrm{~mm}^{[1-16]}$.

O processo criogênico é um processo que resfria os pneus inservíveis a uma temperatura abaixo de menos $120^{\circ} \mathrm{C}$, utilizando nitrogênio líquido. Neste processo os pedaços de pneus de 50,8 mm são resfriados em um túnel contínuo de refrigeração e logo após são lançados em um granulador. No granulador os pedaços são triturados em um grande número de tamanhos de partículas, enquanto, ocorre ao mesmo tempo, a liberação das fibras de nylon, rayon e poliéster e do aço. O granulado de borracha deve estar muito frio antes de sair do granulador, logo em seguida, o material é classificado. Este processo apresenta baixo custo de manutenção e consumo de energia, por outro lado, apresenta um alto custo operacional devido ao consumo do nitrogênio líquido. A operação de redução requer um baixo consumo de energia e as maquinas de trituração não são tão robustas quando comparadas com aquelas do processo de trituração à temperatura ambiente. Outra vantagem deste processo é a fácil liberação do aço e das fibras de nylon, rayon e poliéster, obtendo um produto final limpo ${ }^{[1]}$.

\section{Recapagem, Recauchutagem e Remoldagem de Pneus}

O pneu é reconstruído a partir de um pneu usado, onde se repõe uma nova banda de rodagem, podendo incluir a renovação da superfície externa lateral, abrangendo os seguintes métodos e processos: recapagem, recauchutagem e remoldagem.

O processo de recapagem consiste na remoção da banda de rodagem, no reparo estrutural da carcaça com cordões de borracha e na utilização de cimento para colar a banda de rodagem na carcaça. Os ombros dos pneus não são removidos neste processo.

$\mathrm{O}$ processo de recauchutagem consiste na remoção da banda de rodagem e dos ombros do pneu. Existem dois processos para recauchutagem dos pneus: o processo a frio um método mais eficiente e a recauchutagem a quente, que demanda menos espaço e oferece um ganho de produtividade.

O processo a frio utiliza bandas pré-curadas que são coladas nas carcaças após os reparos das mesmas. São utilizados outros componentes para o reparo e união entre a carcaça e a banda de rodagem, que são: o coxim, que é uma lâmina fina de borracha que vai entre a carcaça e a banda pré-curada; e o cordão de borracha utilizado para preencher furos e danos estruturais do pneu. Para a recauchutagem a quente é utilizada uma manta de borracha, na qual é necessária a utilização de moldes para a vulcanização e a formação do desenho na banda de rodagem. No processo a frio o desenho já está prévulcanizado nas bandas de rodagem a serem aplicadas nas carcaças dos pneus já reparadas. Além disso, em tal processo os pneus são vulcanizados em autoclaves, não necessitando de moldes para a formação do desenho no pneu ${ }^{[19]}$.

$\mathrm{O}$ processo de remoldagem de pneus consiste em remover a borracha das carcaças, de talão a talão, em seguida o pneu é totalmente reconstruído e vulcanizado, sem qualquer emenda, proporcionando balanceamento, apresentação e segurança de uso ${ }^{[19]}$. 


\section{Recapagem e Recauchutagem de Pneus}

Poucos pneus de automóvel são reformados nos Estados Unidos devido a fatores econômicos ${ }^{[20]}$ e também pela percepção do consumidor, que os pneus de automóvel recauchutados são inseguros ${ }^{[20]}$.

A Figura $7^{[2,18,21,22]}$ mostra o cenário internacional da reforma de pneus de ônibus e caminhão. O índice de recapabilidade (IR), que é definido com sendo a quantidade de pneus reformados sobre a quantidade de pneus novos, no Japão: é de 0,23, enquanto que no Brasil: é de 3,25, na Europa de 0,87 , e nos Estados Unidos é igual a 1,2. A Europa e Japão possuem baixos índices de recapabilidade pois grande parte dos pneus de ônibus e caminhão, após o término da primeira vida são exportados.

$\mathrm{Na}$ Europa a recapabilidade restringiu-se a uma reforma por pneu, além disso, a atividade de reforma é considerada "verde" e as empresas recebem incentivos para a montagem de empresas de reforma de pneus.

O Brasil e os Estados Unidos importam grande parte dos pneus usados da Europa e do Japão para a reforma.

Existe uma série de vantagens da recapagem e recauchutagem de pneus, entre elas: empregam 25\% do material utilizado na fabricação de um pneu novo; o pneu é o segundo custo do transporte rodoviário; o pneu depois de reformado apresenta rendimento semelhante ao pneu novo, com custo $70 \%$ menor; os pneus de carga são reformados em média duas vezes, gerando três vidas para cada carcaça; economizam 57 litros de petróleo por pneu reformado, ou seja, repre-

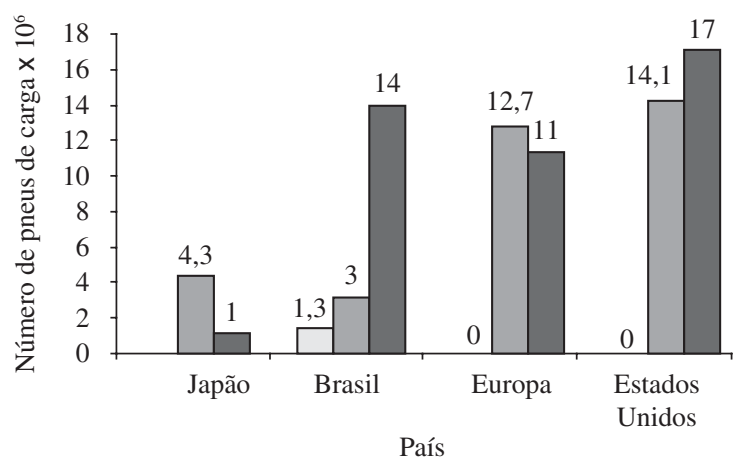

$$
\square \text { Pneu diagonal } \square \text { Pneu radial } \square \text { Pneu reformado }
$$

Figura 7. Demanda de pneus de carga novos e recauchutados em $2004^{[2,17,19,21]}$.

Tabela 3. Custo da reforma dos pneus no mercado mundial e no Brasil ${ }^{[17]}$.

\begin{tabular}{lccc}
\hline \multicolumn{1}{c}{$\begin{array}{c}\text { Reformado/ } \\
\text { novo }\end{array}$} & $\begin{array}{c}\text { Mercado } \\
\text { mundial }\end{array}$ & Brasil & $\begin{array}{c}\text { Quantidade } \\
\text { de reformas }\end{array}$ \\
\hline $\begin{array}{l}\text { Carga (ônibus } \\
\text { caminhão) }\end{array}$ & 33 a $50 \%$ & 18 a $25 \%$ & 2 \\
Automóvel & 40 a $50 \%$ & 40 a $50 \%$ & 1 \\
Moto & - & $33 \%$ & 1 \\
Avião & - & - & $8(*)$ \\
\hline
\end{tabular}

(*) $85 \%$ dos pneus de avião são reformados. $100 \%$ das Companhias Aéreas reformam os pneus. senta uma economia de 798 milhões de litros de óleo diesel/ ano no Brasil; postergam a destinação final da carcaça, reduzindo com isso os impactos negativos ao ambiente.

O custo para reforma dos pneus no Brasil é bem inferior ao praticado no mercado mundial, conforme a Tabela $3^{[18]}$.

\section{Remoldagem de Pneus}

Na Europa, 20\% dos veículos de passeio e utilitários, $50 \%$ da frota de caminhões e $98 \%$ dos aviões das linhas aéreas internacionais utilizam pneus remoldados ${ }^{[19]}$. No Brasil este mercado está crescendo. Em 2006 foram produzidos 2,4 milhões de pneus remoldados ${ }^{[19]}$.

As carcaças de pneus usados entram no Brasil vindas da Europa, Estados Unidos e Japão através de liminares. A tendência para os próximos anos é o aumento da produção de pneus remoldados no Brasil, conforme mostra a Figura 8.

O pneu remoldado custa em média $30 \%$ a $50 \%$ a menos que um pneu novo ${ }^{[23]}$, o que acaba atraindo a atenção do consumidor no momento da compra.

Segundo a Associação Brasileira da Indústria de Pneus Remoldados - ABIP, das 10,5 milhões de carcaças usadas importadas em 2005, 4 milhões foram remoldados, 3 milhões foram recauchutadas, 2 milhões estão estocadas e 1,5 milhão de carcaças foram vendidas como pneus meia-vida ${ }^{[24]}$.

Existe uma série de vantagens para a remoldagem de pneus, entre elas ${ }^{[19]}$ : a relação de resistência ao movimento é 3\% maior quando comparado com os pneus novos; usam 2,3 vezes menos energia, 1,8 vezes menos ar comprimido, 25 vezes menos água quando comparado com os pneus novos; reduzem as emissões, poluição da água e resíduos produzidos são baixos quando comparados com os pneus novos; o potencial de aquecimento global é de 1,8 vezes menor que o de um pneu novo; economizam 20 litros de petróleo em comparação ao que é necessário para produzir um pneu tradicional, ou 40 litros no caso de um pneu de caminhonete.

\section{Co-processamento em Fornos de Cimenteiras}

O co-processamento é definido como a utilização de materiais inservíveis pelo seu gerador em um outro processo em que possa agregar valor como matéria-prima ou como energia $^{[25]}$.

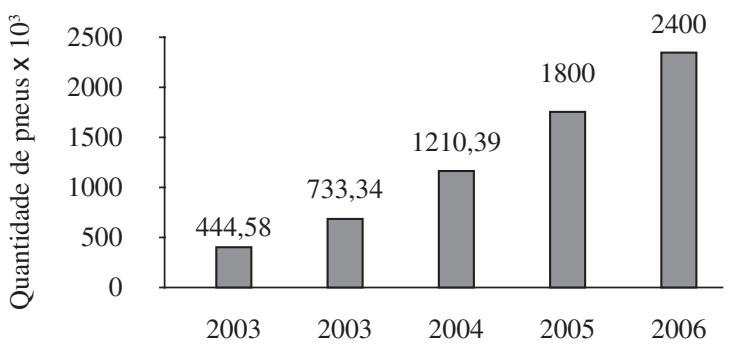

Figura 8. Remoldagem de pneus no Brasil. Empresa de remoldagem que representa $60 \%$ do mercado. 
O co-processamento dos pneus nos fornos de clínquer é uma atividade que proporciona o aproveitamento térmico dos pneus, reduzindo a queima de combustíveis fósseis não renováveis, além disso, incorpora ao clínquer o aço contido nos pneus.

Devido à quantidade de energia requerida em uma fábrica de cimento, as indústrias cimenteiras buscam continuamente alternativas mais econômicas para a utilização dos combustíveis.

Nos Estados Unidos existem 43 fábricas de cimento em 22 estados licenciadas para a utilização dos pneus inservíveis ${ }^{[26]}$. No Japão, em 2003, foram co-processados 130 milhões de pneus usados ${ }^{[2]}$.

As atividades de co-processamento de resíduos iniciaram-se no Brasil na década de 90, no Estado de São Paulo, estendendo-se posteriormente para o Rio de Janeiro, Paraná, Rio Grande do Sul e Minas Gerais ${ }^{[27]}$.

No Brasil, existem 14 fábricas de cimento licenciadas para o co-processamento e $11 \mathrm{em}$ processo de licenciamento ${ }^{[28]}$. A capacidade atual de co-processamento de pneus é de aproximadamente 350.000 toneladas por ano, com potencial para atingir 700.000 toneladas por ano ${ }^{[28]}$.

Em 2006 foram coprocessados 85,96 mil toneladas de pneus inservíveis, o equivalente a 17,19 milhões de pneus de automóvel, ou seja, $35,73 \%$ do total reciclado no ano.

Existe uma série de vantagens com a substituição dos combustíveis tradicionais não-renováveis, utilizados nos fornos, tais como óleo, gás natural e carvão por pneus usados nos fornos de cimenteiras a saber ${ }^{[15,28]}$ : geração em menores quantidades de $\mathrm{SO}_{2}$ e $\mathrm{NO}_{x}$ que os combustíveis tradicionais; aumento da capacidade do clínquer de incorporar, de maneira segura, o aço contido nos pneus; redução do custo de produção do cimento; ambiente de produção do cimento (meio alcalino e presença de sulfatos, além do tempo de residência elevado) dificulta a formação de dioxinas e furanos; alto poder calorífico do pneu. Segundo a United States Environmental Protection Agency (USEPA) ${ }^{[29]}$ o pneu possui a mesma quantidade de energia do óleo utilizado nos fornos de cimento e $25 \%$ a mais com relação ao carvão; redução dos impactos ambientais negativos da extração e transporte; eliminar por completo todos os resíduos devido a combustão completa do pneu; substituição de 10 a $30 \%$ dos combustíveis não-renováveis; permitem a estabilidade térmica durante a queima; permitem absorver todos os pneus usados gerados no país.

Os pneus inservíveis usados no co-processamento em fornos de clínquer devido ao seu alto poder calorífico, são substitutos do óleo combustível e do carvão, a ponto de alguns não os caracterizarem como resíduo e sim os considerem combustíveis ${ }^{[30]}$.

Atualmente o custo para o co-processamento de pneus é de cerca de US\$15 a 20 por tonelada de pneu.

\section{Co-processamento de Pneus com a Rocha de Xisto Pirobetuminoso}

No passado, muitos laboratórios e plantas piloto fizeram várias tentativas para formar unidades econômicas de pirólise de pneus, contudo, o processo não era viável economicamente ${ }^{[31]}$

No Brasil, em 1998, a Petrobras começou a fazer alguns testes para fazer o co-processamento dos pneus junto com a rocha de xisto pirobetuminoso.

O processo Petrosix, foi desenvolvido para a retortagem do xisto, por meio de pirólise a $480{ }^{\circ} \mathrm{C}$. Após ser minerado a céu aberto, o xisto passa pelos britadores primários e secundários, os quais reduzem a granulometria do material bruto na faixa de 11 a $80 \mathrm{~mm}$, que é transportado até a retorta, com a utilização de transportador de correias. Os pneus triturados, em tiras ou pedaços de 50 a $100 \mathrm{~mm}$, são transportados perpendicularmente do silo de alimentação de pneus até o transportador de correia de xisto cru. A taxa de alimentação para a retorta é de $5 \%$ de pneus triturados e $95 \%$ de rocha de xisto pirobetuminoso. O material já misturado é transportado até a parte superior da retorta, e é descarregado pelo topo, assim a carga segue o seu fluxo naturalmente. Para evitar as emissões fugitivas, do processo para a atmosfera, durante o carregamento da retorta, é feita a selagem do topo, pela injeção de gases inertes (nitrogênio e gás carbônico), bem como a selagem do fundo da região de descarga do xisto e do aço contido nos pneus, com água utilizada no processo. Após a descarga do xisto e do aço contido nos pneus pelo topo da retorta, ocorrem à secagem e a retortagem, pela passagem do gás no fluxo inverso ao da carga. Este aquecimento provoca a vaporização da matéria orgânica contida no xisto e pneus, gerando gás e óleo ${ }^{[32]}$.

A energia necessária para a pirólise é fornecida pela corrente endógena de gás do processo aquecido externamente, até cerca de $480{ }^{\circ} \mathrm{C}$, quando é reinjetado na zona de retortagem. Na zona posterior e anterior a zona de retortagem, de resfriamento e aquecimento respectivamente, a massa gasosa ascendente troca calor com o material retortado e se resfria, resultando na condensação dos vapores de óleo sob a forma de neblina, que é transportada para fora da retorta pela corrente de circulação dos gases. As gotículas de óleo passam pelo processo de separação tipo ciclones e filtro precipitador eletrostático. No precipitador, ocorre a separação das gotículas de óleo e das partículas sólidas do ciclone. O gás limpo é isento de neblina de óleo e partículas sólidas, as gotículas de óleo pesado são condensadas, passam por um compressor e se dividem em três correntes: uma retorna para o fundo da retorta, outra também volta à retorta após ser aquecida em um forno, e a terceira denominada gás produto, vai para um condensador de óleo leve e as águas geradas no processo são recuperadas. Depois de retirado o óleo e a água de retortagem, o gás é encaminhado à unidade de tratamento de gases onde são produzidos os gases combustíveis, o gás liquefeito de xisto e onde é processado o enxofre ${ }^{[32]}$.

Os produtos resultantes deste processo são: gás combustível que é utilizado na indústria da cerâmica; enxofre utilizado na indústria de papel e celulose, indústria de explosivos, indústria açucareira, indústria de borracha e agricultura; o GLX (Gás Liquefeito de Xisto) é utilizado na indústria cerâmica; 
e óleo combustível para a indústria e nafta. Os subprodutos resultantes deste processo são: cinzas de xisto, utilizadas como insumo na indústria de cimento; torta oleosa, utilizada como combustível sólido alternativo à lenha e ao carvão mineral; finos de xisto, como combustível e em cerâmica; e a água de retortagem, para a produção de adubo e defensivos agrícolas ${ }^{[32]}$. O negro de fumo, contaminado pelo processo, volta para as minas de xisto. O negro de fumo pode ser utilizado como combustível para termoelétrica, com poder calorífico de $7812 \mathrm{kcal} / \mathrm{kg}$ ou insumo para as indústrias de cerâmica. $\mathrm{O}$ aço e o negro de fumo são descartados na mina juntamente com o xisto retortado ${ }^{[32]}$.

Neste processo, denominado Petrosix, para cada 1 tonelada de pneus co-processados são gerados: $530 \mathrm{~kg}$ de óleo, $40 \mathrm{~kg}$ de gás, $300 \mathrm{~kg}$ de negro de fumo e $100 \mathrm{~kg}$ de aço.

Em 2006 foram utilizadas neste processo 2,48 mil toneladas de pneus inservíveis, o equivalente a 497,19 mil pneus de automóvel, ou seja, 1,03\% do total da reciclagem do ano, mas a Petrobras tem capacidade para absorver 27 milhões de pneus usados por ano.

Atualmente o custo para o co-processamento de pneus é de cerca de US\$ 43 por tonelada.

O que falta para atingir o máximo da capacidade instalada é uma constância no fornecimento dos pneus inservíveis para o co-processamento. Apenas uma das unidades de retortagem faz o co-processamento de pneus inservíveis com a rocha de xisto pirobetuminoso.

\section{Queima de Pneus em Caldeiras}

As caldeiras podem trabalhar com óleo mineral BPF, lenha, bagaço e pneus inservíveis. Os pneus inservíveis estão sendo utilizados como combustível para caldeiras desde 2003. O consumo médio é de 150 mil pneus usados por mês ${ }^{[34]}$.

O processo utiliza 5\% em massa de pneus inservíveis triturados e $95 \%$ em massa do bagaço da cana-de-açúcar, o poder calorífico da mistura chega em torno de $2150 \mathrm{kcal} / \mathrm{kg}$, gerando vapor de baixa-pressão. A alimentação nas caldeiras é feita através de silos dosadores de pneus triturados e bagaço de cana-de-açúcar ${ }^{[34]}$.

Em 2004 foram queimados em caldeiras 1,8 milhões de pneus usados no Brasil. Não foi divulgada a quantidade de pneus inservíveis utilizados como combustível em caldeiras no período de 2005 e 2006. O custo para a queima dos pneus usados nas caldeiras é de cerca de US\$14 por tonelada.

\section{Pavimentação Asfáltica}

Muitos países têm desenvolvido legislação para direcionar seus departamentos de estradas de rodagem a investigar a possibilidade de utilização de materiais recicláveis em obras de pavimentação ${ }^{[36]}$.

Nas misturas asfálticas, existem dois processos: o processo úmido e o processo $\operatorname{seco}^{[36]}$. No processo úmido são adicionadas borrachas com granulometria $0,6 \mathrm{~mm}$, no cimento asfáltico de petróleo - CAP, produzindo um novo tipo de ligante denominado "asfalto-borracha". No processo seco, partículas de borracha substituem parte dos agregados pétreos. Após a adição do ligante forma-se um produto denominado "concreto asfáltico modificado pela adição da borracha" ${ }^{[36]}$.

As misturas de asfalto-borracha têm sido bastante empregadas nos Estados Unidos, principalmente nos estados do Arizona, Califórnia, Flórida e Texas, em trabalhos de recuperação estrutural de pavimentos degradados, em camadas de revestimentos de pavimentos novos e também em serviços de manutenção corretiva ${ }^{[35]}$.

No Brasil a utilização do asfalto-borracha ainda é incipiente, não existe nenhum incentivo por parte do governo para a utilização do asfalto-borracha. A primeira aplicação no Brasil foi feita em agosto de 2001. As concessionárias das rodovias privatizadas estão fazendo alguns testes com a aplicação do asfalto-borracha que tem inúmeras vantagens, entre elas ${ }^{[34]}$ : aumentar a vida útil do pavimento em $30 \%$, quando comparado com o asfalto convencional; retardar o aparecimento de trincas e selar às já existentes; reduzir a espessura da camada aplicada, em até 50\%, quando comparada a projetos que usam o asfalto convencional; apresentar potencial para utilização de um número significativo de pneus usados; reduzir o ruído e a manutenção do pavimento, entre outros.

\section{Desvulcanização}

O processo de desvulcanização envolve duas etapas distintas, a redução de tamanho e a quebra de ligações químicas que pode ser feita através de quatro processos com custos e tecnologias bem diferenciados. Existem aproximadamente 25 tecnologias de desvulcanização que estão desenvolvidas ou em fase de desenvolvimento no mundo. Entretanto, um pequeno número de tecnologias de desvulcanização está em operação no momento ${ }^{[37]}$.

Serão mostrados a seguir os processos de desvulcanização que já estão sendo utilizados comercialmente e os processos que foram desenvolvidos ou estão em fase de desenvolvimento ${ }^{[1,9,12,36-39]}$.

\section{Processos de Desvulcanização Comerciais}

No Brasil, o processo de desvulcanização utilizado comercialmente é o de desvulcanização química ou processo de regeneração da borracha.

A regeneração é um processo de desvulcanização onde os pneus depois de triturados, são submetidos à temperatura, pressão, recebem oxigênio e vapor de produtos químicos, como álcalis e óleos minerais, dentro de uma autoclave rotativa. Os pneus usados são cortados em lascas ou raspas que passam por um processo de moagem mecânica, onde são transformados em pó-de-borracha e tratados por um sistema de separação com peneiras e cilindros magnéticos. Em seguida, em autoclaves rotativas, que utiliza o vapor saturado, o material recebe oxigênio e é submetido a uma temperatura de 
$180^{\circ} \mathrm{C}$ e a uma pressão de 15 bar, provocando o rompimento das pontes de [enxofre-enxofre] e [carbono-enxofre] entre as cadeias poliméricas. Assim, a borracha é transformada em material passível de novas formulações. A massa de borracha resultante deste processo sofre uma trituração mecânica, aumentando com isso a viscosidade, para depois ser prensada. No final do processo, o material ganha a forma de fardos de borracha. Esta borracha pode ser utilizada na formulação de novos artefatos de borracha com demanda e aplicações limitadas, pois possuem propriedades mecânicas inferiores quando comparadas com a borracha original. $\mathrm{O}$ material regenerado tem várias aplicações, tais como: cobrir áreas de lazer e quadras esportivas, tapetes para automóveis, passadeiras, saltos e solados de sapatos, colas e adesivos, câmaras de ar utilizado em pneus convencionais ou diagonais, rodos metálicos, tiras para indústrias de estofados, entre outras aplicações ${ }^{[41]}$.

Em 2006, foram utilizados 31,8 mil toneladas de pneus inservíveis, o equivalente a 6,36 milhões de pneus de automóvel, ou seja, 13,22\% do total reciclado no mesmo ano.

\section{Processos de Desvulcanização que estão Desenvolvidos ou em Fase de Desenvolvimento}

Serão apresentados a seguir os processos de desvulcanização por ultra-som, por bactérias e por microondas.

No processo de desvulcanização por ultra-som, a borracha dos pneus é triturada e as partículas de borracha são carregadas em uma caçamba, alimentando uma extrusora que comprime e estica a borracha alternativamente. A ação mecânica aquece e amolece a borracha. O sistema de ultra-som é instalado no centro ou no ponto de descarga da extrusora, ou seja, a borracha nestas regiões está submetida à energia ultrasônica. Na saída da extrusora existe um tanque com água, utilizado para o resfriamento da borracha. A combinação de calor, pressão e ação mecânica são suficientes para desvulcanizar a borracha.

No processo de desvulcanização biológico ou por bactérias, o conceito de utilização de bactérias para a desvulcanização de resíduos de borracha tem sido investigado nos últimos $30 \operatorname{anos}^{[1,12,38,39]}$. Partículas de borracha são expostas em uma solução aquosa com bactérias que consomem o enxofre e compostos de enxofre, como por exemplo o thibacillus, rodococcus e o sulfolobus. Com a utilização deste processo, podem ser incorporadas as fabricações de pneus novos $15 \%$ de borracha reciclada sem alterar a qualidade dos pneus novos $^{[12,38]}$.

O processo de desvulcanização por microondas aplica energia térmica rápida e uniformemente sobre a borracha. Entretanto, a borracha vulcanizada para ser utilizada no processo de desvulcanização por microondas, deve ter uma estrutura polar, que permita a absorção da energia a uma taxa adequada, para viabilizar a desvulcanização, porém a borracha da grande maioria dos pneus, não possui essa estrutura polar, limitando a sua aplicação $0^{[9]}$.
Tabela 4. Custos e capacidades de produção de borracha desvulcanizada pelo processo químico e por ultra-som ${ }^{[36]}$.

\begin{tabular}{lcc}
\hline \multicolumn{1}{c}{ Item } & $\begin{array}{c}\text { Processo } \\
\text { químico }\end{array}$ & $\begin{array}{c}\text { Processo } \\
\text { ultra-som }\end{array}$ \\
\hline Capacidade $(\mathrm{kg} / \mathrm{h})$ & 34 & 34 \\
Custo (Capital) $\left(\mathrm{US} \$ \times 10^{3}\right)$ & 166 & 163 \\
Custo de Operação e & 172 & 136 \\
Manutenção $\left(\mathrm{US} \$ \times 10^{3}\right)$ & & \\
\hline
\end{tabular}

A seguir serão apresentados os impactos ambientais dos processos químico e ambiente, além disso, os custos e a capacidade de produção.

As principais informações disponíveis sobre impactos ambientais do processo de desvulcanização são limitadas aos processos químicos e por ultra-som. Em ambos os casos há emissões de poluentes atmosféricos e efluentes líquidos. $\mathrm{O}$ trabalho da Calrecovery Inc., lista aproximadamente $50 \mathrm{com}$ postos orgânicos emitidos durante o processo, dentre eles: benzeno, tolueno, heptano, entre outros. Existe a possibilidade de liberação de $\mathrm{H}_{2} \mathrm{~S}$ e $\mathrm{SO}_{2}$ gerados como resultado de oxidação do $\mathrm{H}_{2} \mathrm{~S}$. Assim sendo, o processo necessita filtros para controle de emissões e lavadores de gases para retirada do $\mathrm{SO}_{2}$. Quanto aos efluentes líquidos provenientes do lavador, estes deverão ser tratados adequadamente antes de seu lançamento no corpo receptor ${ }^{[37]}$.

A Tabela 4 apresenta os custos e as capacidades de produção de borracha desvulcanizada, dos processos químicos e por ultra-som.

\section{Laminação de Pneus}

O processo de laminação consiste em diversas operações de cortes efetuadas em pneus inservíveis, para extrair lâminas e trechos de contornos definidos. As empresas que trabalham com o processo de laminação de pneus possuem uma estrutura de coleta de pneus convencionais ou diagonais. Estes pneus não possuem, em sua construção, as malhas de aço, o que facilita a sua reciclagem. Além destes pneus, alguns laminadores estão utilizando pneus radiais inservíveis para a laminação. Os talões dos pneus radiais e diagonais e as bandas de rodagem com lonas de aço dos pneus radiais, não são aproveitadas no processo de laminação, devido à dificuldade da realização do processo de corte e devem ser adequadamente descartados. Os talões e bandas de rodagem devem ser reciclados em um dos processos anteriormente descritos. Os pneus laminados são utilizados em diversas aplicações, tais como: indústria de estofados, indústria de calçados, fazendas, fábricas de rodos, tubos para águas pluviais, tubos para combate a erosões e passagem de níveis, solados, saltos e palmilhas de pneus e percintas para sofás, solados de calçados, tiras para móveis, sofás e poltronas, cestos, e inúmeras outras aplicações ${ }^{[42]}$.

O processo de laminação de pneus é uma atividade de baixo custo e que não causa impactos ao meio ambiente, desde que os resíduos gerados pelo processo, sejam correta- 
mente descartados e devidamente acondicionados durante o processo.

No Brasil, em 2006, foram utilizados no processo de laminação, trituração e fabricação de artefatos de borracha, 120,36 mil toneladas de pneus inservíveis o equivalente a 24,07 milhões de pneus inservíveis, ou seja, 50,02\% do total reciclado no ano. No processo de laminação é utilizado o pneu convencional. A tendência para este tipo de pneu é a diminuição gradativa da produção em todo o mundo, com o incremento da produção dos pneus radiais.

\section{Avaliação das Tecnologias Utilizadas para a Reutilização, Reciclagem e Valorização Energética dos Pneus}

A Figura 9 apresenta todas as tecnologias utilizadas no Brasil para a reutilização, a reciclagem e a valorização energética dos pneus. Pode-se observar que quanto maior o volume, menor o custo e a tecnologia empregada para destinar os pneus servíveis e inservíveis. A atividade de pré-tratamento é uma atividade que apresenta um alto custo para a reciclagem dos pneus.

O resíduo gerado no processo de reforma dos pneus pode ser utilizado na pavimentação asfáltica após o processo de peneiramento, ou exportados como matéria-prima para fabricação de artefatos de borracha.

\section{Conclusão}

Neste trabalho foi feito um levantamento de todas as tecnologias utilizadas no Brasil para a reutilização, reciclagem e a valorização energética. Além disso, foi constatado que a logística reversa tem um papel importante no processo de coleta, triagem, pré-tratamento e disposição final dos pneus. Foi constatado que em 2004, os consumidores levaram para casa mais de 8,2 milhões de pneus, sendo que o destino final destes pneus não é conhecido. Embora este trabalho tenha sido realizado no período de 2002 a 2006, os dados referentes a quantidades de pneus que esses consumidores levaram para casa não foi informada. Atualmente, não existe nenhuma pesquisa acerca de sua destinação.

Em 2006, foram reciclados 240,62 mil toneladas de pneus inservíveis, o equivalente a 48,12 milhões de pneus de automóvel. Desde 2005 a Resolução no 258/99 encontra-se em revisão pelo IBAMA. O cálculo para a definição do objetivo para a reciclagem de pneus foi criado a partir desta Resolução, segundo a qual seria necessário manter um percentual acima do nível de produção para eliminar o passivo ambiental existente, ainda que não existisse nenhum estudo sobre este cenário, como não existe até o momento.

Considerando o período avaliado, 2002 a 2006, somente no primeiro ano foi atingido o objetivo da reciclagem.

De todas as tecnologias utilizadas para a reciclagem de pneus no Brasil, três têm um enorme potencial de reciclar os pneus gerados pelo Brasil anualmente: a atividade de reforma, a valorização energética e a laminação e fabricação de artefatos de borracha. A utilização de pneus na pavimentação asfáltica no Brasil ainda é incipiente.

Em 2006, foram reformados no Brasil 17,8 milhões de pneus servíveis. Esta atividade não é considerada pelo IBAMA, como uma atividade de reciclagem e sim como uma atividade

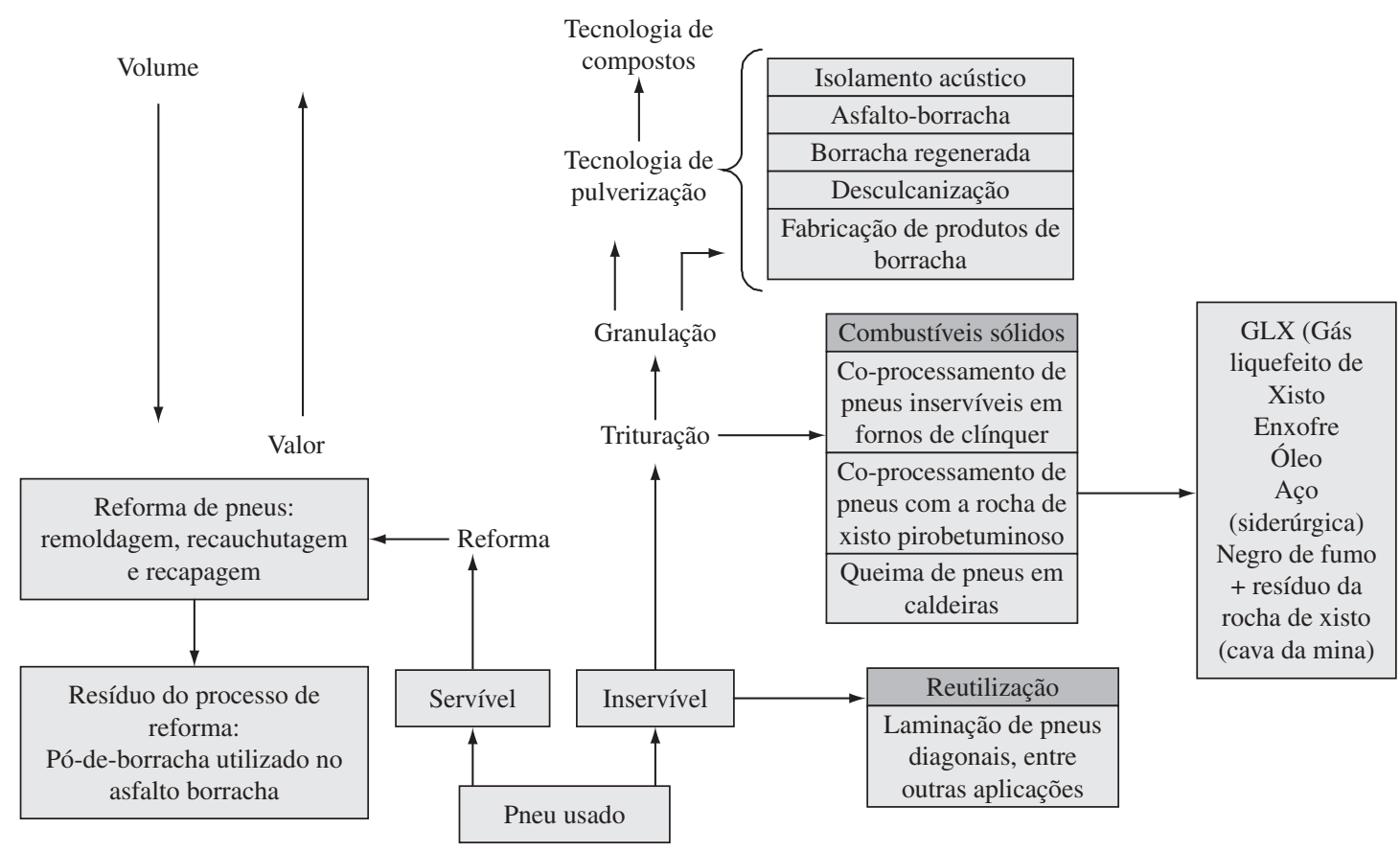

Figura 9. Fluxograma das tecnologias utilizadas para a reutilização, reciclagem e valorização energética. 
que prolonga a vida útil do pneu. Esta atividade deveria ser considerada como um dos processos de reciclagem.

Com a utilização dos pneus como combustível ou matéria-prima nestes processos, ocorre uma redução nos custos operacionais e em alguns casos aumento da produtividade do sistema. A tendência é o aumento do número de cimenteiras licenciadas para o co-processamento de pneus inservíveis em várias regiões do país.

\section{Referências Bibliográficas}

1. Reschner, K. - "Scrap Tire Recycling Page”, Disponível em: <http:www.entire-engineering.de>, acesso em: 12 de novembro de 2002.

2. The Japan Automobile Tyre Manufacturers Association - "Tire Industry of Japan”, Yokohama Rubber, Tokyo (2007).

3. Associação Nacional das Indústrias de Pnemáticos Disponível em: < http://www.anip.com.br>, acesso em 12 agosto de 2007.

4. Aliceweb - "Consulta dos pneus exportados e importados no período de 2002 a 2006", Disponível em: $<$ http://www.aliceweb.desenvolvimento.gov.br/consulta-nova/consulta.asp $>$, acesso em: 12 de Setembro 2007.

5. Conselho Nacional do Meio Ambiente - "Resolução $\mathrm{n}^{\circ} 258$, de 26 de agosto de 1999", Disponível em: <http://www.mma.gov.br/port/conama/res/res99/ res25899.html>, acesso em: 13 de janeiro de 2003.

6. Instituto Nacional de Metrologia, Normalização e Qualidade Industrial -"Portaria $\mathrm{n}^{\circ}$ 5, de 14 de janeiro de 2000, Inmetro: São Paulo (2000).

7. Instituto Nacional de Metrologia, Normalização e Qualidade Industrial - "Nota Técnica DQUAL/DIPAC no 083/2000 de 03 de outubro de 2000", Inmetro: São Paulo (2000).

8. Instituto Nacional de Metrologia, Normalização e Qualidade Industrial - "Portaria no 133, de 27 de Setembro de 2001, Inmetro: São Paulo (2001).

9. Adhikari, B., De, D. \& Maiti, S. - Prog. Polym. Sci., 25, p.909 (2000).

10. Instituto Brasileiro do Meio Ambiente e dos Recursos Naturais Renováveis - "Instrução Normativa $n^{\circ} 8$, de 15 de maio de 2002", IBAMA: Brasília (2002).

11. Marganha, M. F. B. \& Komatsu, C. E. - "Pneus como alternativa energética", in: Anais do $5^{\circ}$ Congresso Brasileiro de Cimento - ABCP, 10 p., São Paulo, novembro (1999).

12. Reis C. \& Ferrão P. - "PROTAP - Produção, utilização e opções de fim de vida para pneus", Instituto Superior Técnico, Lisboa (2000).
13. U.S. Environmental Protection Agency - Disponível em: <http://www.epa.org>, acesso em: 14 de abril 2006.

14. Leite, P. R. - "Logística reversa meio ambiente e competitividade”, Prentice Hall, São Paulo (2003).

15. Lagarinhos, C. A. F. - "Reciclagem de Pneus: Coleta e Reciclagem de pneus. Co-processamento na Indústria de cimento, Petrobras SIX e Pavimentação Asfáltica”, Dissertação de Mestrado, Instituto de Pesquisas Tecnológicas do Estado de São Paulo, Brasil (2004).

16. Granutech-Saturn Systems - "Let the system work for you: complete turnkey solutions for reducing scrap tires to high-quality crumb rubber", Granutech-Saturn Systems Corporation, Grand Prairie (2006).

17. Reciclanip. $2^{\circ}$ Seminário Regional Sul de Resíduos Sólidos - Londrina, julho/07, $29 \mathrm{p}$.

18. Associação Brasileira do Segmento de Reformas de Pneus - Disponível em: <http://www.abr.org.br/indicadores>, acesso em: 15 de setembro de 2007.

19. Associação Brasileira da Indústria de Pneus Remoldados - Disponível em: <http://www.abip.com.br/abip/ pneu/pne_beneficios.php $>$, acesso em: 14 de janeiro de 2005.

20. U.S. Environmental Protection Agency \& Pacific Environmental Services - "Scrap Tires Technology and Markets", Noyes Data Corporation, New Jersey (1993).

21. Rubber Manufactures Association - "U.S. Scrap Tires Markets 2005 Report". Disponível em: <http://www. rma.org>, acesso em: 10 de julho de 2007.

22. European Association of the Rubber Industry - Disponível em: <http://www.blic.be>, acessada em: 24 de janeiro de 2006.

23. Morães, S. \& Rios, C. - Gazeta Mercantil. São Paulo, 16 fev., C5, (2006).

24. Silva, C. - O Estado de São Paulo. São Paulo, 16 fev., B8, (2006).

25. Degré, J. P. - "Co-processing of Alternative Fuels \& Alternative Raw Materials (AFR) - The Holcim experience", in: Trabalhos Apresentados no Workshop: Co-processamento de resíduos na indústria de cimento, 56 p., Belo Horizonte, julho (2003).

26. Portland Cement Association - "Sustainable Manufacturing Fact Sheet: Tire Derived Fuel"; Portland Cement Association: Skokien (2005).

27. Maringolo, V. - "Clínquer coprocessado: produto de tecnologia integrada para sustentabilidade e competitividade da indústria de cimento", Tese de Doutorado, Universidade de São Paulo, Brasil (2001).

28. Furtado, M. - Química e Derivados, 436, p. 12 (2006).

29. U.S. Environmental Protection Agency - "Tire Derived Fuel", Disponível em: <http://www.epa.gov/epaoswer/ non-hw/muncpl/tires/tdf.html>, acesso em: $14 \mathrm{de}$ dezembro de 2003. 
30. Marques, M. - Revista Gerenciamento Ambiental, 6, p.10 (1999).

31. De Marco Rodriguez, I.; Laresgoiti, M. F.; Cabrero, M. A.; Torres, A.; Chamon, M. J. \& Caballero, B. - Fuel Process. Technol., 72, p.19 (2001).

32. Novick, R. E. M.; Martignoni, B. N. V. \& Paes, E. "Retortagem de Pneus", in: Anais do Seminário Nacional sobre Reuso e Reciclagem de Resíduos Sólidos - SMA, 11p., Rio de Janeiro, agosto (2000).

33. PETROBRAS SIX. Processo Petrosix com pneus. São Mateus do Sul-PR: Petrobras SIX, 2003, 2p.

34. Cocamar Cooperativa Agroindustrial - Disponível em: $<$ http://www.cocamar.com.br>, acesso em: 15 de setembro de 2007.

35. Edel, G. - "Pneus inservíveis e asfalto: União que beneficia estradas e o meio ambiente", in: Anais do Simpósio sobre obras rodoviárias RODO, 2 - ABGE, p.105, São Paulo, setembro (2002).

36. Estakhri, C. K.; Joe, Button, W. \& Fernando, E. G. "Use, Availability, and Cost-Effectiveness of Asphalt Rubber in Texas", Transportation Research Record: Washington (1992).
37. Cal Recovery, Inc. - "Evaluation of Waste Tire Devulcanization Technologies", Integrated Waste Management Board: Sacramento (2004).

38. Pacific Northwest National Laboratory. "Discover Award Winners" - Disponível em: <http://www.pnl.gov/main/ welcome/awards/discover/index.html>, acesso em: 25 de janeiro 2006.

39. Fukomori, K. \& Matsushita, M. - R\&D Review of Toyota CRDL, 38, p.1 (2003).

40. Amari, T.; Themelis, N. J. \& Wernick, I. K. - Resources Policy, 25, p.179 (1999).

41. Morandi, A. H. - "Reciclagem de Borracha", in: Anais do Seminário de Materiais (Reciclagem), 2 - AEA, p. 55-60, São Paulo, (1992).

42. Instituto de Pesquisas Tecnológicas de São Paulo. Identificação da Destinação Final de Pneus Inservíveis - Relatório Técnico IPT/DEES no 71196. São Paulo: IPT, 2004, p. 81.

Enviado: 16/05/07 Reenviado: 10/10/07 Aceito: $30 / 01 / 08$ 